\section{EMBRYRIDDLE Aeronautical University}

SCHOLARLY COMMONS
International Journal of Aviation, Aeronautics, and Aerospace

\title{
Cross-Sectional Assessment of Safety Culture Perceptions and Safety Behavior in Collegiate Aviation Programs in the United States
}

\author{
Daniel Kwasi Adjekum \\ University of North Dakota, kadjekum@yahoo.com \\ Julius Keller \\ Purdue University, keller64@purdue.edu \\ Micah Walala \\ Purdue University, micahwalala@gmail.com \\ John P. Young \\ Purdue University, jpy@purdue.edu \\ Cody Christensen \\ South Dakota State University, cody.christensen@sdstate.edu \\ Randal J. DeMik \\ Lewis University, demikra@lewisu.edu

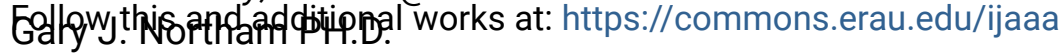

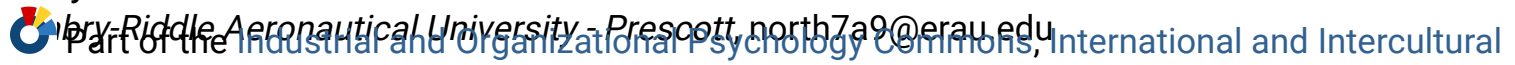 \\ Communication Commons, Interpersonal and Small Group Communication Commons, Organization \\ Development Commons, Personality and Social Contexts Commons, Quantitative, Qualitative, \\ Comparative, and Historical Methodologies Commons, and the Work, Economy and Organizations \\ Commons
}

\section{Scholarly Commons Citation}

Adjekum, D. K., Keller, J., Walala, M., Young, J. P., Christensen, C., DeMik, R. J., \& Northam, G. J. (2015). Cross-Sectional Assessment of Safety Culture Perceptions and Safety Behavior in Collegiate Aviation Programs in the United States. International Journal of Aviation, Aeronautics, and Aerospace, 2(4). https://doi.org/10.15394/ijaaa.2015.1074

This Article is brought to you for free and open access by the Journals at Scholarly Commons. It has been accepted for inclusion in International Journal of Aviation, Aeronautics, and Aerospace by an authorized administrator of Scholarly Commons. For more information, please contact commons@erau.edu. 
Cross-Sectional Assessment of Safety Culture Perceptions and Safety Behavior in Collegiate Aviation Programs in the United States

\section{Cover Page Footnote}

Special thanks to the chairs, faculty, and students of the aviation departments of the universities that facilitated this research. 
There are some inherent safety risks in collegiate flight training programs in the United States (US). A positive safety culture is one fundamental element in managing these risks (Stolzer, Halford \& Goglia, 2011). An important facet of a positive safety culture is the nurturing of good safety behavior and practices (von Thaden, 2008). The evaluation of safety culture may assist in improving safety culture by identifying strengths and weakness in an organization's safety program (Patankar, 2003; Evans, Glendon \& Creed, 2007).

However, von Thaden (2008) suggests using safety culture perceptions to predict safety-reporting behavior in flight operations could be a major challenge. In a previous study, Adjekum (2014) utilized a cross-sectional design to analyze the safety culture perceptions of flight students at an Upper Midwestern flight program in the US. A major obstacle identified in the study was the lack of validated survey instruments specifically suited for collegiate aviation operations.

Adjekum (2014) recommended further validation of research instruments through subsequent studies, using larger sample sizes, and expanding participant recruitment efforts to include multiple institutions. The recommendation also suggests further development of the research instrument called the Collegiate Aviation Program Safety Culture Assessment Survey (CAPSCAS). Details of the CAPSCAS are discussed in the literature review.

The current study used an adapted version of the CAPSCAS to assess the safety culture perceptions of flight students, some of whom were certified flight instructors (CFIs). The purpose of the current study was to investigate how respondents' safety culture perceptions influenced safety reporting behavior. Researchers involved in this study sought to obtain a diverse sample population from both larger and smaller programs. Respondents were recruited from five collegiate aviation programs in the US. The five collegiate aviation programs were geographically located in the Midwest, Upper Midwest and Southwest.

The scope of this study was limited to collegiate flight students, inclusive of those with certified flight instructor (CFI) certificates and enrolled in academic courses in the various programs (respondents). For analysis, respondents were split into two categorical groups: flight students without flight instructor ratings and those with at least one form of flight instructor ratings [Certified flight Instructor (CFI), Certified Flight Instructor Instrument (CFII), Multi-Engine Instructor (MEI)].

The primary objective of the study was to determine safety culture perception variables that predicted safety-reporting behavior (safety reporting frequency). Another objective of the study was to determine if there were any 
significant differences in safety reporting behavior (safety reporting frequency) among demographic variables including age, student enrollment status (international or domestic) and gender. In order to have a clearer understanding of factors that influenced safety culture perceptions and safety reporting, open-ended questions were also included.

This study falls in line with the recommendations of the International Civil Aviation Organization (ICAO) standards and recommended practices (SARPs) and Federal Aviation Administration (FAA). These two aviation entities recommend among aviation organizations in a technologically evolving environment, a continuous sustainability of a positive operational safety culture, and adoption of Safety Management Systems (SMS) in (ICAO, 2009; FAA, 2010).

\section{Literature Review}

\section{Defining and Building a Safety Culture}

Safety culture has various definitions (Piers, Montijn, \& Balk, 2009). Consequently, a lively debate in professional circles regarding the distinction between safety culture and safety climate has evolved (Patankar, 2003; Australian Transportation Safety Bureau, 2004; Wiegmann, Zhang, von Thaden, Sharma, \& Gibbons, 2004). For the purposes of this study, safety culture had a two-pronged definition:

(a) The set of enduring values and attitudes regarding safety issues, shared by every member of every level of an organization (Piers, Montijn \& Balk, 2009, p. 5).

(b) A set of shared values, actions and behaviors that demonstrates a commitment to safety over competing goals and demands (Cooper, 2000 p. 113).

A culture of safety is the product of individual and group values, attitudes, competencies, and patterns of behavior that determine the commitment, style and proficiency of an organization's safety programs (ICAO, 2009). In a desired safety culture, people acknowledge their accountability and act on their individual responsibility for safety. In a proactive organizational safety culture, front-line personnel, trust, use, and rely on the organization's processes for managing safety (ICAO, 2009). The organizational environment is characterized by good and effective communication between management and personnel. An organization's personnel can learn from training and coaching as well as feedback from safety 
reports (FAA, 2008). A core rationale of a good safety program is to create a positive safety culture to improve system-wide safety (IATA, 2011).

An important attribute of a positive safety culture is the development of a proactive safety awareness of front-line personnel. These individuals should understand hazards and associated risks (ICAO, 2009). A hazard is defined as "a condition or an object with the potential to cause injuries to persons, damage to equipment or structures, loss of material, or reduction of the ability to perform a function" (ICAO, 2009, p.4-1, para.4.2.3). A risk is the probability and severity of a hazard (ICAO, 2009). The International Civil Aviation Organization safety management manual (SMM) recommends adequate safety awareness training for front-line personnel, in order to positively influence the operational safety environment. Risk mitigation efforts should be part of the training and education process (ICAO, 2013).

Previous studies have suggested negative safety culture perceptions of personnel could influence safety behavior resulting in incidents and accidents (Hunter, 2006; Dillman, Voges, \& Robertson, 2010; Chen, 2014). According to Cooper (2000), incidents and accidents may lead to loss of lives, damage to equipment, tarnished reputations, and loss of confidence by customers. An individual's perception of the safety culture in an organization is not only influenced by the physical environment of the organization, but also by the organization's commitment to safety (Cooper, 2000).

Risk perception may influence safety reporting behavior (Hunter, 2006). Accidents and incidents may increase safety risk awareness. However, accidents and incidents may also create negative perceptions of safety (Hunter, 2006). Even when personnel are aware of all the contributing aspects of such safety occurrences, individual attributes and differences in perceptions may influence personnel reporting behavior (Hillson \& Murray-Webster, 2004). Risk perception is a critical antecedent of risky behavior (Wilde, 2001). In order for personnel to voluntarily report hazards, risk perception must be enhanced through effective safety education and training (Chen, 2014).

\section{Safety Culture and Diversity Issues in U.S. Collegiate Flight Training Programs}

Collegiate flight programs have become more diversified. Some programs provide international contract pilot training for foreign airlines and governments. Safety risks perceptions and reporting behavior may be influenced by culture (Hunter, 2006; NTSB, 2010; Stolzer, Halford \& Goglia, 2011). Inattention to 
differences in cultural norms and peculiarities of safety values may negatively affect an aviation program's safety and reputation (ICAO, 2009; NTSB, 2010). Routine and consistent safety culture assessments should capture the effects of national culture and diversity in flight training (Hunter, 2006; Stolzer, Halford \& Goglia, 2011). Therefore, it is important to include international students in the analysis for this study.

Freiwald, Lenz-Anderson and Baker (2013) assessed the safety culture within a multi-national and multi-campus flight training organization. Results from the study indicated that respondents agreed on the importance of a safety reporting system. However, neither of the respondents participated in the company's reporting system, nor were respondents familiar with the current status of the reporting system. The authors recommended safety behavior and perceptions of international flight students be further examined to understand similarities and differences to domestic flight students (Freiwald, Lenz-Anderson, \& Baker, 2013).

\section{Cross-Sectional Design}

A cross-sectional design reveals how variables are represented in a crosssection of a population. Cross-sectional designs generally use survey techniques to gather data. In this study, a cross-sectional design was used to capture safety culture perceptions of respondents. Some of the inherent limitations of a cross-sectional design are the difficulty in measuring change, the effect of confounding variables on outcomes, increased chances of error, and difficulty in establishing cause and effect (Creswell, 2009)

\section{The Collegiate Aviation Perception of Safety Culture Assessment Survey (CAPSCAS)}

The Collegiate Aviation Perception of Safety Culture Assessment Survey (CAPSCAS) is a survey instrument adopted from the Commercial Aviation Safety Survey (CASS). Validation measures of both instruments showed sufficient reliability and internal consistency (Adjekum, 2014). The CAPSCAS consists of sixty-nine items under six major underlying dimensions: Formal Safety (FS), Informal Safety (IS), Operations Interactions (OI), Organizational Commitment (OC), Aviation Department Safety Record (ADSR), and Safety Behavior (SB). Each of the six major dimensions mentioned have sub-scales. These sub-scales are shown in Table 1A of Appendix A.

The Safety Value (SV) sub-scale is defined as the attitudes and values regarding safety, expressed in words and actions by collegiate aviation leadership. 
The Safety Fundamentals (SF) sub-scale is defined as how an aviation organization is set up in relation to compliance with regulated aspects of safety such as training requirements, Standard Operating Procedures (SOPs) and other technical manuals. The Reporting System (RS) refers to the accessibility, familiarity, and actual use of the aviation operator's formal safety reporting program by operational personnel and end users such as aviation students.

The Response and Feedback (RF) sub-scale entails the timeliness and appropriateness of management responses to reported safety information, and dissemination of safety information to operational personnel. It is also a measure of the quality of feedback on safety reports by the organization's leadership to relevant personnel. The Aviation Department Safety Record (ADSR) is the respondent's perception of the overall safety record and regulatory compliance capabilities of the organization. It is also an effective gauge of the probability of safety and regulatory violations.

The Safety Behavior (SB) sub-scale is the outcome variable and is defined as the frequency of voluntary self-reporting of safety issues through the established reporting procedures existing in the aviation department by respondents. An assumption for this study was self-reporting of safety issues by respondents were driven by perceptions of the safety culture in the operations of the aviation department (Adjekum, 2014).

\section{Research Purpose and Questions}

The purpose of the study was to assess the relationship between the safety culture perceptions and the safety reporting behavior of respondents (flight students, including those who were certified flight instructors) in five collegiate aviation programs in the US. The following research questions were addressed:

1. What are the safety culture perception indicators that predict the safety reporting behavior of respondents?

2. What are the differences in safety reporting behavior between respondents with and without certified flight instructor (CFI) ratings based on their safety culture perceptions?

3. How do safety culture perceptions of participants when grouped under demographic variables such as gender and enrollment status, affect safety reporting behavior, when the variable CFI rating is controlled? 


\section{Method}

This study adopted survey items from the CAPSCAS. Sub-scales from the Reporting System category were used. These sub-scales included Response and Feedback (RF), Safety Value (SV), Safety Fundamental (SF), Aviation Department Safety Record (ADSR), and Safety Behavior (self-reporting of safety issues). The selection of these sub-scales was exploratory and researchers sought to examine the responses to the sub-scales items and the effect on respondents' SB (in this case safety reporting behavior). Table 1 indicates the number of items within each sub-scale.

Table 1

Items in the sub-scales of CAPSCAS used for the study

\begin{tabular}{lc}
\hline Sub-scale & Number of items \\
\hline Reporting System (RS) & 7 \\
Respond and Feedback (RF) & 5 \\
Safety Value (SV) & 5 \\
Safety Fundamental (SF) & 5 \\
Aviation Department Safety Record & 3 \\
(ADSR) & \\
Safety Behavior (SB) & 2 \\
\hline
\end{tabular}

The respondents were asked to rate perceptions on items of the survey instrument using a five point Likert scale. Respondents were given the option to provide demographic information, such as gender, age, international/domestic enrollment status, and education level to enhance data analysis. Finally, respondents were asked the number of times they had self-reported safety issues in their programs (reporting frequency). The quantitative data was uploaded and coded appropriately into IBM SPSS $® 21$ statistical software package for analysis.

The multi-item scales were the independent variables and indicators of safety culture perceptions. The dependent variable was Safety Behavior (frequency of voluntary self- reporting of safety issues). In terms of the qualitative component of this study, respondents were given an opportunity to provide answers to open-ended questions. The open-ended questions pertained to safety reporting system confidentiality, safety office personnel receptiveness, and suggestions for improvement. Responses were coded manually and emerging themes were identified. The themes were then coalesced to help provide a qualitative explanation to selected Likert-scale responses. See Appendix B for the CAPSCAS survey instrument. 


\section{Survey Administration, Sample and Data Collection Management}

After Institutional Review Board (IRB) approval was obtained, appropriate email lists were obtained from each of the five participating programs. A convenience sampling method was used and an email including the survey link was distributed. The survey was open for four weeks during the spring semester of 2015. The estimated sample population was approximately five hundred $(N=500)$. At the end of the response period, four hundred and eighty one $(N=481)$ respondents accessed the link to the survey. Two hundred and twenty two $(n=222)$ respondents did not proceed beyond the consent page. Two hundred and fifty nine ( $n=259$ [51.8\%]) responses were completed beyond the consent page and used for analysis.

\section{Results}

\section{Factor Analysis}

An Exploratory Factor Analysis (Principal Axis Factoring) was conducted on each scale using a varimax rotation. Items with strong loading on factors were extracted from each set of items in the sub-scales. Strongly loaded items on each factor were identified using the scree plot of the SPSS® output by retaining all factors before the line levels off, and under the following conditions:

1. Communalities less than 0.4.

2. Eigen values greater than 1 .

The factors and percentage of variance explained by the Eigen values were determined. After the factors were extracted, the reliability of the scales was determined using the Cronbach's Alpha test in SPSS®. Generally, for social sciences, an alpha $(\alpha)$ of .70 and above indicates high internal consistency (Stevens, 2002; Fields, 2009).

In the Reporting System (RS) scale, an initial extraction yielded a one-factor solution with approximately $41 \%$ of the variances explained by the Eigen values. Items RS1_1, RS1_2, RS1_3, RS1_6, and RS1_7 loaded strongly on a single factor. Items RS1_4 and RS1_5 showed weak loading and were deleted. Reliability analysis was conducted on the RS scale using SPSS $®$ and the initial alpha was $\alpha=$ .80. However, the reliability could have been improved to .82 if item RS1_6 had been deleted. Since the reliability $\alpha=.80$ and $\alpha=.82$ were close and adequate, RS1_6 was retained.

In the Response and Feedback (RF) scale, the factor analysis yielded a onefactor solution, with about $47.4 \%$ variances explained by the initial Eigen values. Item RF1_4, which was reverse-coded was removed due to weak loading and the analysis was re-run. The new result yielded the same one-factor solution. Initial 
reliability analysis produced $\alpha=.75$, and when RF1_5 was dropped and the reliability re-run, the result yielded $\alpha=.81$, which was adequate and an improvement.

In the Safety Value (SV) scale, a one-factor solution was obtained after SV1_1 was removed due to weak loading on other factors. Even though item SV1_5 was reverse -coded, the factor loading was negative. The result suggested that, the respondents did not either understand the item or rated it wrongly. Due to this ambiguity, SV1_5 was not used for further analysis. The variances explained by the Eigen values were approximately $43.6 \%$. Reliability analysis was conducted on the remaining three items and the Cronbach's Alpha value was .73, which was determined adequate.

There was only one factor for the Safety Fundamentals (SF) scale and all items in the scale were retained. Approximately $57.2 \%$ of the variance was explained and reliability of $\alpha=.81$. In the case of the Aviation Department Safety Record (ADSR), due to the limited number of items, only reliability analysis was conducted and an alpha value of $\alpha=.78$ was obtained. All the items that were retained in the various scales after the factors extraction and reliability analysis were summed and used for further analysis. The descriptive statistics on the summed scales was conducted and the results were determined to be consistent with the assumptions of a normally distributed data. The assumption of normality was confirmed based on histograms with normality plot and the kurtosis and skewness values of the descriptive statistics tables. The values were in the acceptable range of -1 to +1 .

\section{Demographic Analysis}

One-hundred and ninety-nine males (76.8\%) and 42 females (16.2\%) responded to the survey. Eighteen $(6.9 \%)$ respondents did not disclose their gender. In terms of enrollment status, 224 (86.5\%) respondents were domestic (U.S. students) while $17(6.6 \%)$ were international students. Eighteen respondents did not indicate their enrollment status. The respondents comprised of six educational level groups consisting of freshmen, sophomore, juniors, seniors, graduate students, and others. Freshmen and sophomores were the modal groups.

There were $68(26.3 \%)$ freshmen and 69 (26.6\%) sophomores. The rest of the groups were juniors $57(10.3 \%)$ and seniors $43(16.6 \%)$. Graduate student responses consisted of $3(<1 \%)$ and 'others' $2(<1 \%)$. Seventeen $(6.6 \%)$ respondents did not answer this item. In terms of age, $78(30 \%)$ of the respondents were below age 20 . One-hundred and forty three $(55.2 \%)$ of respondents were age 
20-30. Thirteen (1.9\%) of respondents were age 31-40. Five (1.9\%) of the respondents were age $40-51$. There was one $(<1 \%)$ respondent each for age group 51-60 and above 60 years.

A breakdown of the respondents by colleges showed that, out of the five aviation colleges, $4.2 \%$ of the respondents were from the first college; approximately $20 \%$ were from the second college, $20 \%$ from the third college, $11 \%$ from the fourth college and approximately $39 \%$ from the fifth college. Approximately $6.6 \%$ of the respondents did not identify with any college. Table 2 and Table 3 provide a summary of all the demographic data used in the analysis.

Table 2

Demographic variables of Gender, Enrolment Status and Educational level Group

\begin{tabular}{lcc}
\hline \multicolumn{1}{c}{ Variable } & Value & Percentages (\%) \\
\hline Gender & 199 & 76.8 \\
Male & 42 & 16.2 \\
Female & 18 & 7.0 \\
No response & 259 & 100.0 \\
Total & & \\
& & \\
Enrolment Status & 224 & 86.5 \\
Domestic & 17 & 6.6 \\
International & 18 & 6.9 \\
No response & 259 & 100.0 \\
Total & & \\
& & \\
Educational Level & & 26.3 \\
Group & 68 & 26.6 \\
Freshmen & 69 & 22.0 \\
Sophomore & 57 & 16.6 \\
Junior & 43 & 1.2 \\
Senior & 3 & \\
Graduate & 2 & 0.8 \\
Students & 17 & 6.6 \\
Others & 259 & 100.0 \\
No response & & \\
Total & & \\
\hline
\end{tabular}

Note. Percentages are approximate values. 
Table 3

Demographic Variables of Colleges and Age Groups

\begin{tabular}{ccc}
\hline Variables & Values & Percentages $(100 \%)$ \\
\hline Colleges/Institutions & 10 & \\
1 & 52 & 2.0 \\
2 & 52 & 20.0 \\
3 & 28 & 11.0 \\
4 & 101 & 39.0 \\
5 & 16 & 6.0 \\
No response & 259 & 100.0 \\
Total & & \\
& & 30.1 \\
Age Group & 78 & 55.2 \\
Below 20 & 143 & 5.0 \\
$20-30$ & 13 & 1.9 \\
$31-40$ & 5 & 0.4 \\
$41-50$ & 1 & 0.4 \\
$51-60$ & 1 & 6.9 \\
Above 60 & 18 & 100.0 \\
No response & 259 & \\
Total & &
\end{tabular}

Note. Percentages are approximate values.

The demographic distribution for the flight certificates of respondents (CERTS) indicated there were 101 respondents (39\%), who had at least one form of certified flight instructor ratings and classified as such. Respondents who did not indicate any form of certified instructor ratings were $158(61 \%)$. The details of the certificate break down for all the various categories of flight certificates are shown in Table 4 and Table 5. 
Table 4

Certificates and Ratings of Respondents (Respondents checked all ratings that applied)

\begin{tabular}{lc}
\hline $\begin{array}{l}\text { Certificates ( Check all that } \\
\text { applies) }\end{array}$ & Number of Respondents \\
\hline Students & 129 \\
Private & 147 \\
Commercial Single Engine (SE) & 109 \\
Commercial Multi-Engine (ME) & 108 \\
Certified Flight Instructor (CFI) & 101 \\
Certified Flight Instructor & 89 \\
Instrument (CFII) & 84 \\
Multi-Engine Instructor (MEI) & 3 \\
Airline Transport Pilot (ATP) & \\
\hline
\end{tabular}

Table 5

Categorical details of the number of respondents with flight instructor ratings

\begin{tabular}{lcc}
$\begin{array}{l}\text { Classification as } \\
\text { Certified Flight } \\
\text { Instructor (CFI) }\end{array}$ & $\begin{array}{c}\text { Number of } \\
\text { Respondents }\end{array}$ & Percentages \\
\hline Yes & & \\
No & 101 & 39.0 \\
Total & 158 & 61.0 \\
\hline
\end{tabular}

\section{Research Question 1}

What are the safety culture perception indicators that predict the safety reporting behavior of respondents?

In order to answer this question, a bivariate test of correlations was initially used to establish the strength of relationship between the safety culture perception of respondents and their safety reporting behavior (Repfreq) in collegiate aviation programs in the US. This analysis was conducted, to find out variables that were linearly related, and could potentially become viable predictors in the subsequent regression analysis. Table 6 shows the Pearson's Bivariate Correlations of research variables. 
Table 6

Pearson's Correlation of study variables

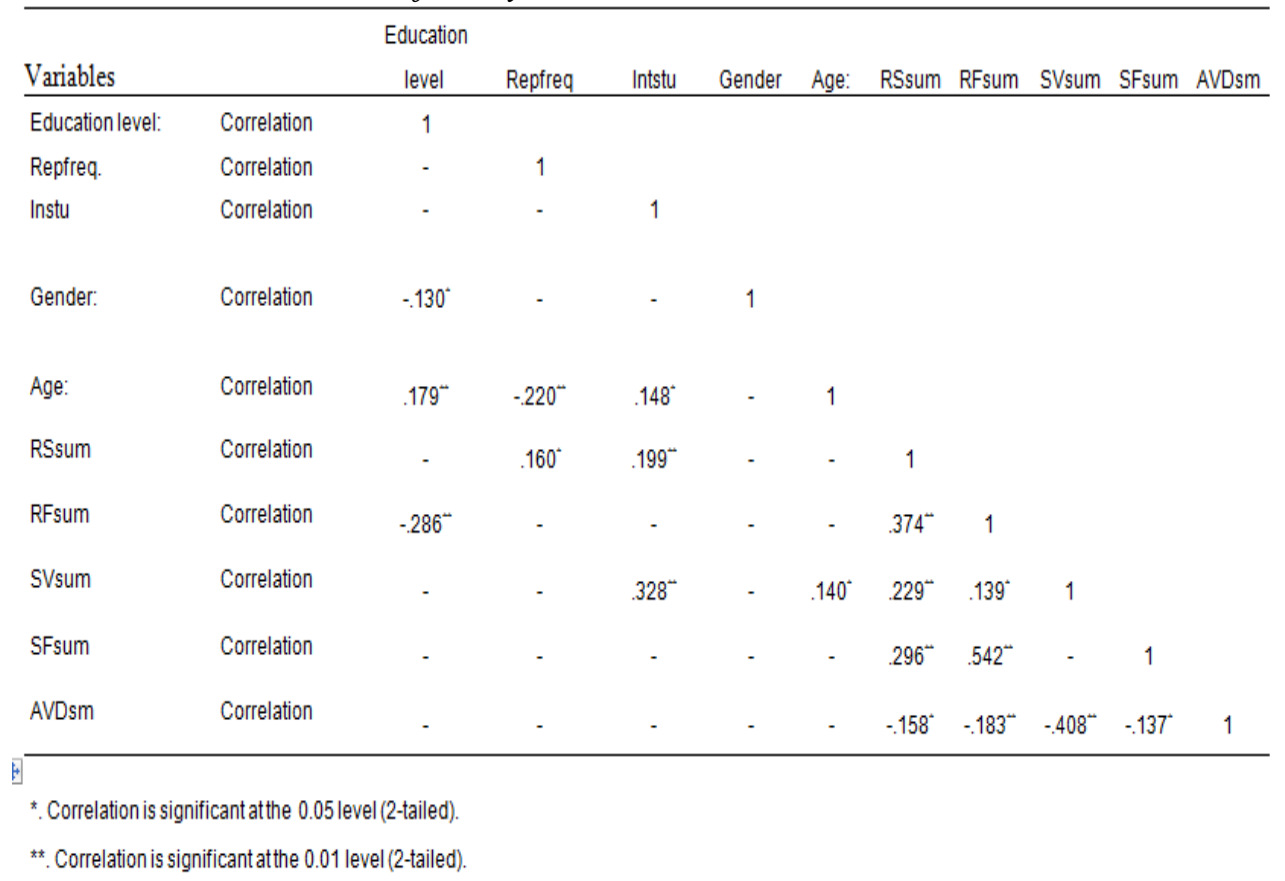

Findings from the analysis show that, the strongest statistically significant positive correlation exist between participant perception on Safety Fundamentals and Response and Feedback, $r(242)=.54, p<.001(2 \mathrm{~T})$. The correlation between safety reporting frequency (Repfreq) and RSsum was positively statistically significant, even though the strength of relation was weak, $r(237)=.16, p<.001$ (2T). The result suggests that although the perceptions of respondents on the safety reporting systems were positive and linearly linked with safety reporting frequency (Repfreq) which defined safety behavior, the strength of relationship, may be weak.

However, a negative statistically significant correlation between safety reporting frequency and the age of respondents existed, $r(240)=-.22, p<.001$ (2T). The result suggests an inverse relationship might exist between participant age and frequency of reporting. There was a positive statistically significant correlation between Safety Values and enrollment status, $r(231)=.33, p<.001$ (2T). Since the student's enrollment status was coded with international contract students as (1) and domestic students as (2), a positive linear trend in the correlation suggests a more favorable perception with Safety Value items and correlates positively with respondents who are domestic. 
There was also a high negative statistically significant correlation between Safety Values (SV) and Aviation Department Safety Record (ADSR).There was a correlation of $r(236)=-.41, p<.001(2 \mathrm{~T})$. This result suggests that as the perception of respondents on the SV in their programs becomes less favorable, the perception that the Aviation Department Safety Record will be tarnished by an accident, incident or cited for safety violations increases.

The result indicates that the safety culture perceptions of respondents might improve if collegiate aviation leadership places a high value on initiatives that projects proactive organizational safety. There was also a small significant negative correlation between Aviation Department Safety Record and Response and Feedback, $r(57)=-.18, p<.001(2 \mathrm{~T})$. This finding indicates respondents expect response and feedback after safety issues are reported. If respondents perceive that feedback from leadership is not forthcoming or on a decline, it can create an unfavorable perception of ADSR.

There was a statistically significant relationship in the negative direction between Response and Feedback (RF) and Educational Level (YearGrp) of respondents, $r(236)=-.29, p<.001$. This result suggests that respondents who have spent more years in the program, have a less favorable perception of RF from their collegiate aviation program leadership in regards to safety issues reported.

Multiple Regression Analysis. In the second part of the research question, multiple regression analysis was used. The scores on Safety Reporting Frequency (Repfreq) used to define safety behavior were predicted from the perceptions of respondents on Reporting Systems, Response \& Feedback, Safety Values, Safety Fundamentals, Education Level, Age, and Aviation Department Safety Records. Preliminary data screening included examination of histograms of scores, skewness and kurtosis of all eight predictor variables. Univariate distributions were determined to be reasonably normal with no extreme outliers.

The first analysis was a forced entry simultaneous Multiple Regressions with all the predictor variables (perceptions). The result shows that the overall model was statistically significant, $F(9,207)=2.78, p<.01(2 \mathrm{~T}), R^{2}=.11$. This result suggests that there was at least a significant predictor of safety reporting behavior among the predictor variables. The predictor variables Age, Reporting System and Safety Fundamental were significant predictors of the outcome variable Safety Reporting Frequency. The individual Beta $(\beta)$ and $t$ values are highlighted below: 
1. $\beta_{\text {age }}=-.19, t(216)=-2.69, p<.01(2 \mathrm{~T})$.

2. $\beta_{\mathrm{RS}}=.18, t(216)=2.41, p<.05(2 \mathrm{~T})$.

3. $\beta_{\mathrm{SF}}=-.18, t(216)=-2.29, p<.05(2 \mathrm{~T})$.

The result indicates that about $11 \%$ of the variances in safety reporting were explained by the combined effect of the predictors, while the individual contribution of the various significant predictors with the safety reporting system was about $18 \%$. A hierarchical Multiple Regressions analysis was conducted with the background variables age, gender and education level. The analysis produced two statistically significant overall models with an $F$-value corresponding to, $F$ (1, $214)=9.53, p<.01(2 \mathrm{~T}), R^{2}=.043$, and $F(1,208)=5.171, p<.05(2 \mathrm{~T}), R^{2}=.095$ respectfully.

The individual predictor Age was a statistically significant predictor in both models. In the first significant overall model, the value of beta was, $\beta_{\text {age }}=-$ $.21, t(214)=-3.08, p<.01(2 \mathrm{~T})$. In the other significant model, the beta value was, $\beta_{\text {age }}=-.18, t(214)=-2.547, p<.05(2 \mathrm{~T})$. The other predictor variables $\mathrm{RS}$ had beta value, $\beta_{\mathrm{RSum}}=.18, t(214)=2.374, p<.05(2 \mathrm{~T})$, and the variable $\mathrm{SF}$ had beta value, $\beta_{\mathrm{SFsum}}=-.18, t(214)=-2.274, p<.05(2 \mathrm{~T})$. The results show that, even though the overall contribution of all the predictor variables in explaining the variances in the model was not substantial ( $\sim 4 \%$ to $10 \%)$, the individual contributions of the significant predictors were decreased in the hierarchical models by the introduction of the background variables such as Age, Gender and Education Level.

\section{Research Question 2}

What are the differences in safety reporting behavior between respondents with and without certified flight instructor (CFI) ratings based on their safety culture perceptions?

An objective of this study was to find out if there was a difference between the frequency of safety reporting of respondents who had CFI ratings, and respondents who did not have the ratings. An independent $t$ - test, which is an inferential statistical test that determines whether there is a statistically significant difference between the means in two unrelated groups, was used for the analysis (Fields, 2009).

In this study, even though the respondents were collegiate students, it was assumed that, respondents who had CFI ratings, fell into a distinct group because they had the capacity to be engaged as CFIs, or were even employed as CFIs in their respective programs. For the purpose of this analysis, the respondents with 
CFI ratings and respondents without CFI ratings were classified into two categorical groups.

The data was assumed normal and the assumption of homogeneity of variance was assessed by the Levene's test, with an $F$-ratio of $F(232)=.82, p>.05$ (2T). The result indicates that the assumptions of equal variance were met; therefore, the equal variances assumed version of the $t$ - test was used. There was no statistically significant differences in the mean frequency of safety reporting of respondents with instructor ratings $(M=2.0, S D=1.15)$, and respondents without instructor ratings $(M=2.0, S D=1.07)$. The $T$ value was, $t(231)=.56, p=.58(2 \mathrm{~T})$ with CI $[(-.21)-(.37)]$.

\section{Research Question 3}

How do the safety culture perceptions of respondents when grouped under demographic variables such as gender and enrollment status, affect their safety reporting behavior, when certified flight instructor ratings is controlled?

An Analysis of Covariance (ANCOVA) was run using SPSS® General Linear Model (GLM) to determine how safety culture perceptions of demographic groupings such as gender, and enrollment status affect safety-reporting behavior (frequency of safety reporting), when flight instructor experience is used as a covariate. The reason for the covariate was to control for the effects of both academic and operational flight experiences gained through the CFI ratings. One of the possible effects of the CFI ratings was the relatively higher flight experience and institutional operational knowledge when compared to non-CFI rated respondents in the collegiate aviation environment.

The experience of these respondents with CFI, coupled with an organizational and regulatory requirement such as professional adherence to collegiate aviation program standard operating procedures (SOPs), could indirectly coerce them to report issues that may affect safety of flight during flight instruction. The researchers controlled for that effect, to provide a standardized metric to assess how the actual safety culture perceptions of respondents (gender and enrollment status) affected their safety reporting behavior.

The result suggests that there was neither gender main effect, $F(1,232)=$ $.64, p=.45(2 \mathrm{~T})$ or enrollment status main effect, $F(1,232)=1.64, p=.20(2 \mathrm{~T})$. There was no gender* enrollment status interaction effect, $F(1,232)=.58, p=.73$ (2T). The mean plot of the interaction between gender and enrollment status, when CFI ratings was used as a covariate is shown in Figure 1. 


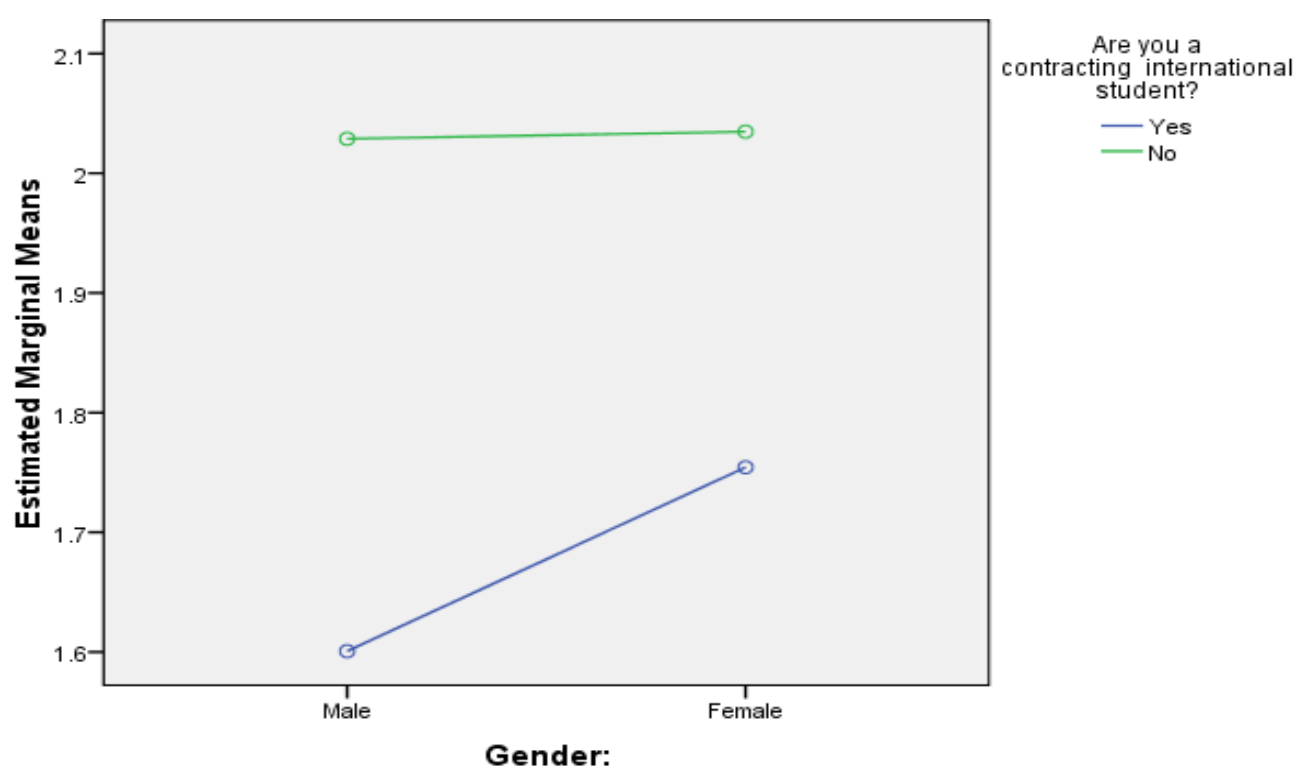

Figure 1. Estimated Marginal Means of Number of Safety Reports in Collegiate Programs

\section{Discussion}

The statistically significant positive correlation between participants' perception of Safety Fundamentals and Response and Feedback corroborated earlier findings by Adjekum (2014). This finding suggests that when collegiate aviation program management provides effective feedback on safety issues reported by respondents, the dividend may be an increased positive perception of the safety culture in the program.

The result also underscores the importance of having a robust safety foundation and framework in collegiate aviation programs. Additionally, the findings accentuate Cooper's (2000) safety culture model, which emphasizes organizational and operational structures that improve compliance with safety regulations. When respondents operate in a proactive safety environment and feel that safety concerns are adequately and expeditiously addressed, respondents may develop a positive perception of the prevalent safety in the program.

A strong positive significant correlation existed between the perceptions of respondents on Reporting System and Response and Feedback. The results suggest that respondents generally identified the essential link between a confidential reporting system and effective response and feedback program. The findings corroborate the Dillman, Voges, and Robertson (2010) study, which included Likert-type data as well as open-ended essay responses on safety reporting and risk 
awareness in the flight-training environment. Additionally, in the findings of Dillman, Voges, and Robertson (2010) study, some of the reasons adduced for ineffective flight training safety reporting systems included: fear of punishment, lack of management support, lack of feedback, lack of a safety priority, and differences in perception of what is considered safe or unsafe.

There was a strong positive significant correlation between perceptions on the Safety Values and Enrollment Status. There were implications that domestic respondents had a more favorable perception of the safety culture in their programs. The finding suggests that collegiate aviation program managers seeking to expand their international flight training programs should ensure that their program's core safety values are robust and accepted from a culturally diverse student population.

The results of this study indicate a significant negative correlation between Aviation Department Safety Record (ADSR) and perceptions of Safety Values. As the perceived value on safety decreased, the perception of respondents on ADSR became less favorable. In addition, the perception of the likelihood of safety violations, incidents and accidents increased. It is therefore imperative for collegiate aviation program managers to ensure operational safety becomes a business function. Imbibing of the core elements of the organizational safety values should become a part of the initial indoctrination process for all new operational personnel, students and employees in collegiate aviation programs. The process should be periodically reviewed for improvements.

The age of respondents, perceptions of the Reporting Systems, and perceptions about the Safety Fundamentals were significant predictors of positive safety reporting behavior. In addition, there was an inverse relationship between age and safety reporting behavior. Within the skewness of the sample in terms of age (majority of whom were relatively young collegiate students), the results suggest that the older the respondents, the lower the frequency for reporting safety issues.

The selected regression model predicts that as respondent perception on the Safety Fundamentals in their programs improves, the frequency of reporting safety related issues by respondents become lower. This observation is worrisome as it suggests that as some respondents' confidence in the existing SF in their programs increases; it may lead to complacency in safety reporting. Respondents may feel less proactive to report safety issues or in a worst-case scenario decide not to report safety issues because they have a favorable perception of the Safety Fundamentals of their aviation program. 
This attitude may be due to complacency and a flawed belief that the existing SF in the program is effective to prevent safety occurrences. On the contrary, the result may also suggests that respondents who have a negative perception of their aviation program's compliance with regulated aspects of safety such as SOPs may be more proactive to report safety issues, and at a higher frequency. The result underscores the need for a proactive implementation of the ICAO Safety Management Manual (2013) recommendations to aviation service providers to continuously review and improve safety programs in order to identify and trap such subtle double- edged risk factors.

The findings also suggest that as the perceptions of respondents on the Reporting System in their programs improves, their propensity to report safety related issues increases (increased safety reporting frequency). This supports the importance of having administrative structures in place to ensure flight personnel are adequately familiar with the process and procedure for reporting safety issues. The need for all operational, technical and administrative personnel to have easy access to safety reporting systems and formats should be emphasized and this important requirements are suggested in the earlier Dillman, Voges, and Robertson's (2010) study.

The results of this study are similar with findings of a previous research by Freiwald, Lenz-Anderson, and Baker (2013) on the safety culture in an aviation training organization in the US. In that study, Freiwald, Lenz-Anderson, and Baker suggested that respondents generally agreed on the importance of a safety reporting system, but did not participate in the organization's safety reporting system nor were they familiar with the status of the reporting system. Leadership of collegiate aviation programs are encouraged to comply with ICAO's SARPs, which emphasize providing all personnel in the program, relevant education on hazards identification, and safety reporting procedures and process.

The age of respondents was a statistically significant negative predictor of safety reporting behavior; the older the respondents, the lower the number of safety issues reported. Notwithstanding the skewness of the sample in terms of age (majority of whom were relatively young collegiate students), this result was at variance with previous findings by Hunter (2006) on risk perceptions among general aviation (GA) pilots. Hunter (2006) suggests that young GA pilots tend to have higher risk tolerance and were unlikely to report hazards, and other operational safety risk. This particular finding indicates that there may be some latent psychosocial factors accounting for the observed trend or the sample size is 
low. Further research with a larger sample sized may provide different results. Additionally, qualitative research may provide further insight.

Intuitively, there was an initial assumption that respondents who had CFI ratings would be more proactive in the reporting of safety issues and have a higher safety reporting frequency than those without CFI. However, there was not a statistically significant difference in the mean reporting frequency between respondents who had CFI ratings and those who did not. This result can be explained based on the assumption that even though some flight students will defer to their CFI for reporting of safety issues during instructional flights, some flight students may also report safety issues from an individual perspective even though their flight instructors may have filed a report. The result highlights the importance of including all students, instructors, and support personnel in safety reporting education.

The perceived experience advantage of flight instructor ratings did not influence the safety culture perceptions of respondents. Flight instructor ratings may not have a confounding effect on the interaction between the demographic variables gender and enrollment status as earlier perceived. However, due to the small sample size and skewness of the gender and enrollment status data, further studies is recommended to understand this interaction.

\section{Qualitative Responses}

Operational Pressure to Complete Flights on Schedule. One of the themes with the highest frequency (7) of mention was how operational pressure to complete flight training at all costs and under "duress" affects safety. In some of the collegiate aviation programs, a flight operations management system has been established to keep students on track with their flight program. The system automatically links the progress of a student's flight activities to a ground- based course. When there are specified numbers of incomplete flight activities within a week, a flight student risks failing the ground course.

Some respondents found this situation worrisome, and at odds with the touted important safety principle of not being pressured to fly under unfavorable conditions. The emerging consensus from the respondents implies pressure to maintain the operational requirements for flight, regardless of unfavorable weather; physiological and psychological variables were inimical to safe flight operations. These are quotes from some of the respondents: 
- \#\#\# is set up for students to promote unsafe actions as they feel a major pressure to fly even if it is in unsafe conditions. Strongly against \#\#\#\# as they can cause unsafe decisions.

- While instructors and officials at my school preach the importance of knowing when to cancel flights, or playing on the safe side in regard to weather, operationally, the opposite is true. However, if we fall behind schedule, or do not complete a certain amount of activities a week (for whatever reason), we fail our ground course, and have to retake it. Therefore, while they preach that you should play it safe and cancel if you feel like you should not fly, in practice, they encourage the opposite. This has been communicated to our course managers, who have dismissed our concerns completely.

Reporting System: Confidentiality. Some respondents felt existing safety reporting systems were not anonymous and could be used to "tattle-tale" on fellow students for non-safety issues. Some respondents felt that it was better to submit the National Aeronautics and Space Administration (NASA) Aviation Safety Reporting System (ASRS). In the opinion of these respondents, ASRS is viewed as more trustworthy and legally protective compared to existing safety reporting systems.

There were allegations and concern that some students were able to strip personal information from existing safety reporting systems. This development is at variance with recommendations by ICAO (2013), which specifies that a safetyreporting program should be confidential, voluntary, and non-punitive. The benefits from such a system are twofold: often personnel are the closest to safety hazards, so the reporting system enables them to actively identify these hazards, and at the same time, management is able to gather pertinent safety hazard information, and build trust with personnel. The following is a quote from as student survey participant:

I agree with my CFI who says, nobody fully trusts or can verify that the system is actually anonymous for those wanting to submit anonymous reports, so you're better off submitting a NASA form which is more trustworthy and has legal protections. I actually know the student who works at the airport who strips personal information from the public releases and it is just some freshman who can see all of your personal data. So there you have it. Improvements needed: Increase the anonymity trustworthiness perception. 
A suggestion to improve the use of confidential safety reports is the appointment of student mediators/ombudsmen. These individuals may act on behalf of others as neutral representatives regarding the management and resolution of safety reports. Class mediators would work alongside the safety office personnel and meet periodically to collate, analyze, and make recommendations on safety issues that are reported at the various collegiate programs.

Safety Office Personnel Receptiveness. Some respondents had the perceptions that safety reports submitted to personnel at the safety office, did not receive the appropriate attention, and the personnel were not receptive. Some respondents stated that occasional arguments over the contents of safety reports between respondents and the personnel at the safety office discouraged them from further reporting any safety issues. However, responses from the survey item "feedback from the safety office for reports filed" recorded a mixed perception. While some respondents stated that responses from the safety office were timely, others expressed divergent opinions.

The varying perceptions suggest there is still work to be done by leadership of collegiate aviation programs in ensuring, that respondents have confidence in the important roles and responsibilities the aviation safety office personnel. The implementation of recommendations from ICAO (2013) for a secure and easy access to safety reporting systems, active safety data collection, and management's proactive treatment of the data may help to address these challenges. Below is a quote from a respondent:

When I made my safety report, the only reason I learned the outcome is that my instructor got an email from someone who fielded our report, when he wanted to know more, and the other party involved apologized. Otherwise, I didn't see my report in the newsletter, and didn't see any topics about it in either the safety seminar or newsletters.

Improving Safety Reporting. There was also the perception that some of the programs had a good Safety Management System (SMS) running. However, there was the need to enhance safety reporting by teaching it as part of the courses for ground school. A respondent actually attested to the perception that courses in safety specialization was very beneficial, as it built the capacity of students to be able to know much about risk management and safety issues that affect flight operations. 
There were also perceptions that a lot of work had to be done by the leadership of collegiate aviation programs to encourage self-reporting of safety issues. Some respondents felt that a comprehensive assurance from collegiate aviation program leadership on the viability of a non-punitive confidential reporting system might improve reporting of safety issues. A suggestion from a respondent is highlighted as follows:

The SMS program at \#\#\# is top notch. The only area that I believe could be improved upon would be self-reporting. Sometimes students or CFIs have been known to not report an incident if no damage was caused. \#\#\# should remind everyone participating in the program that every safety report counts even if it may seem 'minor.'

\section{Conclusion}

A cross-sectional quasi- mixed-method approach was used to determine the relationships between safety culture perceptions and safety reporting behavior among flight students with and without CFI ratings. Respondents were recruited from five collegiate aviation programs in the US. Items adopted from the CAPSCAS were used in the assessment. Researchers sought to find out if the safety reporting behavior (reporting frequency) of respondents could be predicted from their safety culture perceptions. Pearson's Bivariate Correlation, Multiple Regressions, independent $T$-test of means, and Analysis of Covariance were used for data analyses.

The findings indicated the age of respondents, Reporting System and Safety Fundamentals perceptions were statistically significant predictors of safety reporting behavior. Additionally, there was no significant difference in safety reporting frequency between respondents with and without CFI ratings. A major theme from the qualitative part of the study was pressure to fly when conditions were considered unsafe, in order to meet ground course targets. These respondents felt that such pressures placed them under duress to fly when not fully fit psychologically, physiologically, and when the weather was not ideal for flight.

One of the limitations of this study was the small sample size. This may make generalizing results to all collegiate flight students inappropriate. The small number of female participants rendered the study male-gender biased. Equally, the small sample size for international students skewed the data towards domestic students. An assumption was made that there was a difference in academic and operational experience of respondents with CFI and those without. All the study 
respondents were flight students. However, there may be respondents, who may have acquired additional aeronautical experience outside the confines of the program. This may affect their safety reporting behavior.

Cross-sectional studies cannot determine cause and effect relationships. The method is also limited to a snapshot of the safety culture within the study period and may not reflect the general trend over a long period. Furthermore, the anonymity of the survey made it difficult to determine whether respondents took the survey more than once. In addition, due to the dynamic nature of flight operations and the likelihood of specific safety occurrences, this may have influenced the perceptions of respondents.

Researchers of this study recommend an extension of safety awareness and safety reporting programs to all stakeholders involved in the aviation program. Additionally, further validation of collegiate aviation safety culture assessments surveys should be conducted. Qualitative approaches can be effectively utilized to gain a clearer understanding of safety culture perceptions, specifically, how age influences safety reporting behavior. Furthermore, safety culture perceptions between different demographic groups such as management /administration versus students can be compared and contrasted. These recommendations for future research may assist the collegiate aviation community in enhancing positive safety culture. 


\section{References}

Adjekum, D. K. (2014). Safety culture perceptions in a collegiate aviation program: A systematic assessment, Journal of Aviation Technology and Engineering, 3(2). http://dx.doi.org/10.7771/2159-6670.1086

Australian Transportation Safety Bureau. (2004). ATSB aviation safety survey: Safety climate factors. Retrieved from https://www.atsb.gov.au/media/36879/Safety_climate_factors.pdf

Chen, C. F. (2014). Measuring the effects of safety management system practices, morality leadership and self-efficacy on pilots' safety behaviors: Safety motivation as a mediator. Safety Science, 62(14), 376-385.

Cooper, M. D. (2000). Towards a model of safety culture. Safety Science, 36(2), 111-136. http://dx.doi.org/10.1016/S0925-7535(00)00035-7

Creswell, J. W. (2009). Research design: qualitative, quantitative, and mixed method approaches ( $3^{\text {rd }}$ ed.). Thousand Oaks, CA: Sage Publication. Inc.

Dillman, B., Voges, J., \& Robertson, M. (2010). Safety occurrences: Student perceptions regarding failure to report. Journal of Aviation Management and Education, 1(1), 1-14. Retrieved from http://www.aabri.com/manuscripts/09261.pdf

Evans, B., Glendon, A. I., \& Creed, P. A. (2007). Development and initial validation of an aviation safety climate scale. Journal of Safety Research, 38(6), 675-682. http://dx.doi.org/10.1016/j.jsr.2007.09.005

Federal Aviation Administration. (2008). Safety Management System guidelines: Order 8000.369. Washington, D.C.: Author. Retrieved from http://www.faa.gov/documentLibrary/media/Order/8000.369.pdf

Federal Aviation Administration. (2010). Safety Management Systems for aviation service providers: AC 120-92A. Washington D.C.: Author. Retrieved from http://www.faa.gov/regulations_policies/ advisory_circulars/index.cfm/go/document.information/documentID/3192 28 
Fields, A. (2009). Discovering statistics using SPSS. $3^{\text {rd }}$ ed. Thousand Oaks, CA: Sage Publishing.

Freiwald, D., Lenz-Anderson, C., \& Baker, E. (2013). Assessing safety culture within a flight training organization. Journal of Aviation/Aerospace Education and Research, 22(2).

Hillson, D., \& Murray-Webster, R. (2004). Understanding and managing risk attitude. Burlington, VT: Gower Publishing Limited.

Hunter, D. R. (2006). Risk perception among general aviation pilots. The International Journal of Aviation Psychology, 16(2), 135-144. http://dx.doi.org/10.1207/s15327108ijap1602_1

International Air Transport Association. (2011). Safety Management Systems: Implementation and controls handbook. Montreal, Canada: IATA Training and Development Institute.

International Civil Aviation Organization. (2009). Safety management manual (SMM) (Doc. 9859 [2 ${ }^{\text {nd }}$ ed.]) [PDF]. Montréal, Canada: ICAO. Retrieved from http://www.icao.int/safety/fsix/Library/DOC_9859_FULL_EN.pdf

International Civil Aviation Organization. (2013). Safety management manual (SMM) (Doc. 9859/ AN 474 [3 ${ }^{\text {rd }}$ ed.]) [PDF]. Montréal, Canada: ICAO. Retrieved from http://www.skybrary.aero/bookshelf/books/644.pdf

National Transportation Safety Board (2010). Aviation query brief website.

Retrieved from http://www.ntsb.gov/aviationquery/ brief2.aspx?ev_id=20101117X70315\&ntsbno=WPR11FA050\&akey=1

Patankar, M. S. (2003). A study of safety culture in an aviation organization. International Journal of Applied Aviation Studies, 3(2), 243-258. Retrieved from http://www.faa.gov/about/office_org/headquarters_offices/arc/programs/a cademy/journal/pdf/Fall_2003.pdf 
Piers, M., Montijn, C., \& Balk, A. (2009). Safety culture framework for the ECAST SMS-WG. European Commercial Aviation Safety Team (ECAST). Retrieved from https://easa.europa.eu/essi/ecast/wpcontent/uploads/2011/08/WP1-ECASTSMSWGSafetyCultureframework1.pdf

Stevens, J. P. (2002). Applied multivariate statistics for the social science ( $4^{\text {th }}$ ed.). Mahwah, NJ: Lawrence Erlbaum Associates.

Stolzer, A. J., Haldford, C. D., \& Goglia, J. J. (2011). Implementing Safety Management System in aviation. Surrey, England: Ashgate Publishing, Ltd.

von Thaden, T. (2008). Safety culture in commercial aviation operations: Technical report HFD-08-3/FAA-08-1. Savoy, IL: University of Illinois Human Factors Division

Wiegmann, D. A., Zhang, H., von Thaden, T. L., Sharma, G., \& Gibbons, A. M. (2004). Safety culture: An integrative review. International Journal of Aviation Psychology, 14(2), 117-134. http://dx.doi.org/10.1207/s15327108ijap1402_1

Wilde, G.J.S. (2001). Target risk 2: A new psychology of safety and health. Toronto: PDE Publications. 


\section{APPENDIX A}

Table $1 \mathrm{~A}$

A table showing the elements of the CAPSCAS- (Source: Adjekum, 2014)

Scale Sub-scale Number of Items in

FS Reporting System (RS)

Response and

Scale

Feedback (RF)

Safety Personnel (SP)

IS

Accountability (ACC)

Pilot Authority (PA)

Professionalism

14

(PROF)

OI

Supervisors of flight

(SOF)

17

Dispatch (DPT)

Ground/ Ramp

Personnel (GRD)

OC

Safety Values (SV)

Safety Fundamentals

15

(SF)

Going Beyond

Compliance (GBC)

ADSR

Incidents (INC)

Accidents (ACD)

3

Citations from

Violations

SB

Self-Reported (SR)

3

Others (OR)

14 


\section{APPENDIX B}

\section{SURVEY INSTRUMENT - MODIFIED CAPSCAS}

The study analysed the perceptions of flight students and instructors on the safety culture in five Collegiate Aviation Programs and the relationship with safety reporting behavior using the Collegiate Aviation Perception of Safety Culture Assessment Survey (CAPSCAS). Some of the items were reverse coded (REV), however respondents did not see the question code names.

Reporting System: Rate the official reporting system for reporting aviation safety issues and concerns in your aviation department/school.These items will be rated on a 1 - 5 Likert scale

\begin{tabular}{|l|l|}
\hline \multicolumn{1}{|l|}{ STRONGLY DISAGREE } \\
\hline Name & Item \\
\hline RS1_1 & $\begin{array}{l}\text { I am familiar with the concept of safety management systems } \\
\text { (SMS). }\end{array}$ \\
\hline RS1_2 & The safety reporting system is convenient. \\
\hline RS1_3 & The safety reporting system is easy to use. \\
\hline RS1_4 & $\begin{array}{l}\text { Flight students can report safety discrepancies without fear of } \\
\text { negative repercussions. }\end{array}$ \\
\hline RS1_5 & $\begin{array}{l}\text { Pilots are willing to report information regarding marginal } \\
\text { performance or unsafe actions of other pilots. }\end{array}$ \\
\hline $\begin{array}{l}\text { RS1-6 } \\
\text { Reverse } \\
\text { coded) }\end{array}$ & $\begin{array}{l}\text { Pilots do not bother reporting near misses or close calls, since } \\
\text { these events don't cause any real damage. }\end{array}$ \\
\hline RS1_7 & $\begin{array}{l}\text { Pilots are willing to file reports about unsafe situations, even if the } \\
\text { situation was caused by their own actions. }\end{array}$ \\
\hline RS1_8 & $\begin{array}{l}\text { I know how and where to report safety related concerns in the } \\
\text { aviation department. }\end{array}$ \\
\hline
\end{tabular}


Response and Feedback: This item refers to the response pilots receive from your aviation department's safety system

\begin{tabular}{|ccccc|}
\hline STRONGLY DISAGREE & & \multicolumn{2}{c|}{ STRONGLY AGREE } \\
1 & 2 & 3 & 4 & 5 \\
\hline
\end{tabular}

\begin{tabular}{|l|l|}
\hline Name & Item \\
\hline RF1_1 & $\begin{array}{l}\text { Safety issues raised by pilots are communicated regularly to all } \\
\text { other pilots }\end{array}$ \\
\hline RF1_2 & $\begin{array}{l}\text { When a pilot reports a safety problem, it is corrected in a timely } \\
\text { manner }\end{array}$ \\
\hline RF1_3 & $\begin{array}{l}\text { Pilots are satisfied with the way the university deals with safety } \\
\text { reports }\end{array}$ \\
\hline $\begin{array}{l}\text { RF1_4 } \\
\text { (Reverse } \\
\text { Coded) }\end{array}$ & $\begin{array}{l}\text { The aviation department/school only keeps track of major safety } \\
\text { problems and overlooks routine ones }\end{array}$ \\
\hline RF 1_5 & $\begin{array}{l}\text { My aviation department/school keeps a confidential database of } \\
\text { responses and feedback }\end{array}$ \\
\hline
\end{tabular}


Safety Values: These items refer to the values that your aviation department's leadership places on safety.

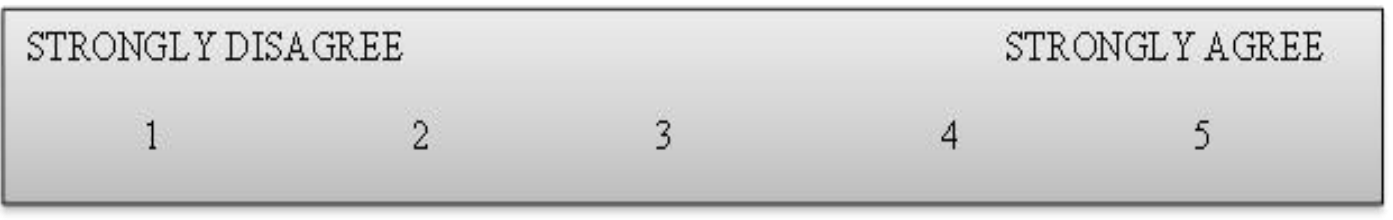

\begin{tabular}{|l|l|}
\hline Name & Item \\
\hline SV1_1 & Safety is a core value in my aviation department. \\
\hline $\begin{array}{l}\text { SV1_2 } \\
\text { Reverse } \\
\text { Coded) }\end{array}$ & $\begin{array}{l}\text { The leadership in my aviation department are more concerned } \\
\text { about making money than being safe. }\end{array}$ \\
\hline $\begin{array}{l}\text { SV1_3 } \\
\text { (Reverse } \\
\text { Coded) }\end{array}$ & $\begin{array}{l}\text { The leadership in my aviation department doesn't show much } \\
\text { concern for safety, until there is an accident or incident. }\end{array}$ \\
\hline SV1_4 & $\begin{array}{l}\text { The leadership in my aviation department does not cut corners } \\
\text { when safety is concerned. }\end{array}$ \\
\hline $\begin{array}{l}\text { SV1_5 } \\
\text { (Reverse } \\
\text { Coded) }\end{array}$ & $\begin{array}{l}\text { The leadership in my aviation department expect pilots to push } \\
\text { for on time performance, even if it means compromising } \\
\text { safety. }\end{array}$ \\
\hline
\end{tabular}




\section{Safety Fundamentals: These items refer to your aviation department's typical practices related to safety in operational areas.}

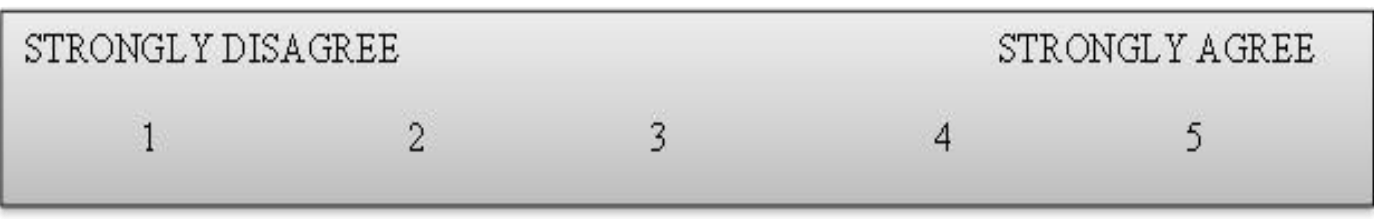

\begin{tabular}{|l|l|}
\hline Name & Item \\
\hline SF1_1 & Checklist and procedures are easy to understand. \\
\hline SF1_2 & $\begin{array}{l}\text { The aviation department's flight operation manuals are carefully } \\
\text { kept up to date. }\end{array}$ \\
\hline SF1_3 & $\begin{array}{l}\text { My aviation department is willing to invest money, resources and } \\
\text { effort to improve safety. }\end{array}$ \\
\hline SF1_4 & $\begin{array}{l}\text { My aviation department is committed to equipping aircraft with up- } \\
\text { to-date technology. }\end{array}$ \\
\hline SF1_5 & $\begin{array}{l}\text { My aviation department ensures that maintenance on aircraft is } \\
\text { adequately performed and that aircraft are safe to operate. }\end{array}$ \\
\hline
\end{tabular}


Aviation Departments Safety Record: This item refers to your perception about the aviation department's safety record within the next twelve months

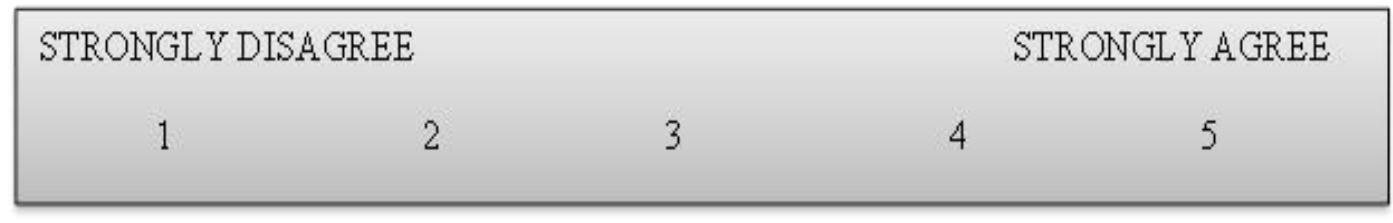

\begin{tabular}{|l|l|}
\hline Name & Item \\
\hline $\begin{array}{l}\text { ADSR1_1 } \\
\text { Reverse } \\
\text { Coded) }\end{array}$ & $\begin{array}{l}\text { Someone in my department is likely to be involved in an } \\
\text { accident over the next twelve months. }\end{array}$ \\
\hline $\begin{array}{l}\text { ADSR1_2 } \\
\text { (Reverse } \\
\text { Coded) }\end{array}$ & $\begin{array}{l}\text { Someone in my department is likely to be involved in an incident } \\
\text { over the next twelve months. }\end{array}$ \\
\hline $\begin{array}{l}\text { ADSR1_3 } \\
\text { Reverse } \\
\text { Coded) }\end{array}$ & $\begin{array}{l}\text { Someone in my department is likely to be cited by the FAA for a } \\
\text { major safety violation over the next twelve months. }\end{array}$ \\
\hline
\end{tabular}




\section{Demographics Questions to all Research Participants}

Please note: this information is for research purposes only and would not be used to identify you personally.

\section{Year Group:}

\begin{tabular}{|l|l|}
\hline Name & Item \\
\hline YEARGRP & (1) Freshman. \\
& (2) Sophomore. \\
& (3) Junior. \\
& (4) Senior. \\
& (5) Graduate Students. \\
& (6) Others (Please specify in space provided). \\
& \\
\hline
\end{tabular}

\section{Gender}

\begin{tabular}{|l|l|}
\hline Name & Item \\
\hline GENDER & (1) Male. \\
& $\begin{array}{l}\text { (2) Female. } \\
\text { (3) Others. }\end{array}$ \\
\hline
\end{tabular}

\section{Are you an International Contract Student?}

\begin{tabular}{|l|l|}
\hline Name & Item \\
\hline INSTU & $\begin{array}{l}\text { (1) Yes. } \\
\text { (2) No. }\end{array}$ \\
& \\
\hline
\end{tabular}

Age

\begin{tabular}{|l|l|}
\hline Name & Item \\
\hline Age & (1) Below 20 \\
& (2) $20-30$ \\
& (3) $31-40$ \\
& (4) $41-50$ \\
& (5) $51-60$ \\
& (6) Above 60
\end{tabular}




\section{Certificates/Ratings acquired (Please check all ratings that apply)}

\begin{tabular}{|l|l|}
\hline Name & Item \\
\hline CERT & (1) Student. \\
& (2) Private. \\
& (3) Commercial-Single Engine. \\
& (4) Commercial -Multi Engine. \\
& (5) Certified Flight Instructor (CFI). \\
& (6) Certified flight Instructor Instrument (CFII). \\
& (7) Multi-Engine Instructor (MEI). \\
& (8) Airline Transport Pilot (ATP). \\
\hline
\end{tabular}

Have you ever reported a safety issue at your university?

\begin{tabular}{|l|l|}
\hline Name & Item \\
\hline REPFREQCAT & $\begin{array}{l}\text { (1) Yes. } \\
\text { (2) No. }\end{array}$ \\
\hline
\end{tabular}

How many times have you reported a safety issue at your university?

\begin{tabular}{|l|l|}
\hline Name & Item \\
\hline REPFREQ & 1 \\
& 2 \\
& 3 \\
& 4 \\
& 5 \\
& Other (Please write figure in space provided below) \\
\hline
\end{tabular}

\section{Open ended questions:}

Briefly describe any recommendations for improving safety in your aviation department.

Please use the space below for any additional comments you have regarding safety in your aviation department. 